\title{
Novel Synthesis of Trisubstituted Olefins for the Preparation of the C16-C30 Fragment of Dolabelide C
}

\author{
Alexander F. Tiniakos, ${ }^{\S}$ Stéphane Wittmann, ${ }^{\S, \dagger}$ Alexandre Audic, ${ }^{\ddagger}$ and Joëlle Prunet* ${ }^{*}$ \\ WESTCHEM, School of Chemistry, University of Glasgow, Joseph Black Building, University Avenue, Glasgow G12 8QQ U.K.
}

Supporting Information

ABSTRACT: A silicon-tether ring-closing metathesis strategy is reported for the synthesis of trisubstituted olefins flanked by allylic or homoallylic alcohols, which are difficult to obtain by classical ring-closing or cross-metathesis reactions. In addition, a novel Peterson olefination reaction has been developed for the preparation of the allyldimethylsilane precursors, which are versatile synthetic intermediates. This method was then applied to the synthesis of the $\mathrm{C} 16-\mathrm{C} 30$ fragment of dolabelide $\mathrm{C}$.

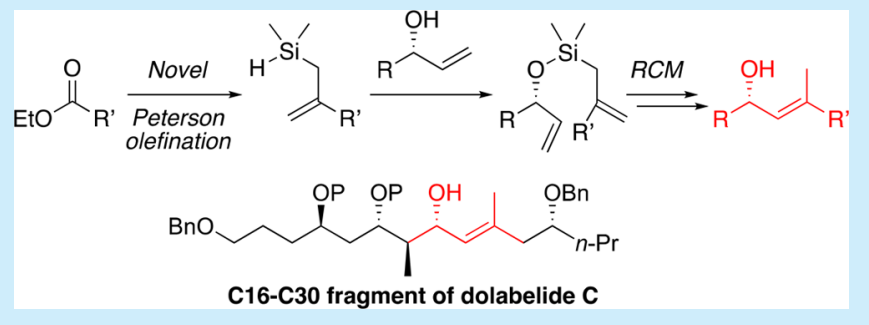

Scheme 1. Synthesis of Trisubstituted Olefins by Metathesis Reactions

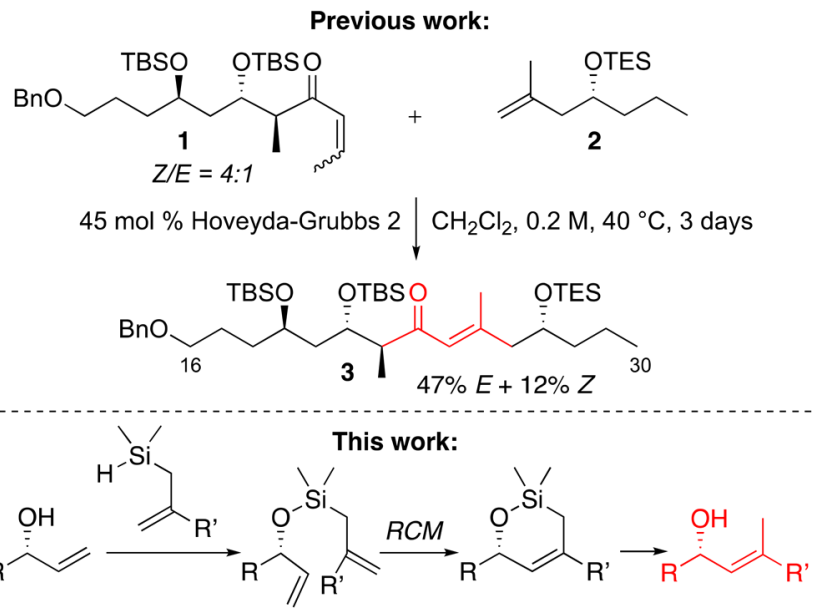

trisubstituted enone 3 was only $47 \%$, because $Z$ enone 1 isomerized into the unreactive $E$ isomer in the presence of metathesis catalysts, showing the limitations of CM for the synthesis of highly hindered trisubstituted olefins. ${ }^{6}$ We thus devised an intramolecular version of this coupling reaction, relying on a silicon-tether ring-closing metathesis. This strategy has been employed frequently in natural product synthesis, but in most cases the silicon is attached to two oxygen atoms. ${ }^{7}$ The $\mathrm{RCM}$ reaction of substrates possessing an $\mathrm{O}-\mathrm{Si}-\mathrm{C}$ linkage is far less common, and there are few examples involving the formation of trisubstituted olefins from allylsilanes, all of which involve cyclic substrates. ${ }^{8}$ Herein we report the synthesis of acyclic trisubstituted olefins by coupling of allylic alcohols with

Received: November 6, 2018

Published: December 27, 2018 
allyldimethylsilanes, followed by RCM and tether cleavage of the resulting silyl ethers (Scheme 1).

The first objective of this work was to find an efficient synthesis of allyldimethylsilanes from easily available starting materials. While numerous examples of conversion of esters into allyltrimethylsilanes by Peterson olefination have been described, ${ }^{9}$ to our knowledge there is no report of the synthesis of the corresponding allyldimethylsilanes using this method. Treatment of esters $\mathbf{4} \mathbf{a}-\mathbf{c}$ with 2 equiv of the Grignard reagent derived from chloromethyldimethylsilane $\mathbf{5}$ in the presence of cerium trichloride, ${ }^{10}$ followed by elimination of dimethylsilanol by stirring the unpurified $\beta$-hydroxysilanes with silica gel in dichloromethane, gave the desired allyldimethylsilanes $\mathbf{6 a - c}$ (Scheme 2). ${ }^{11}$ These silanes are versatile intermediates that

Scheme 2. Synthesis of Allyldimethylsilanes and SiliconTether RCM Reaction

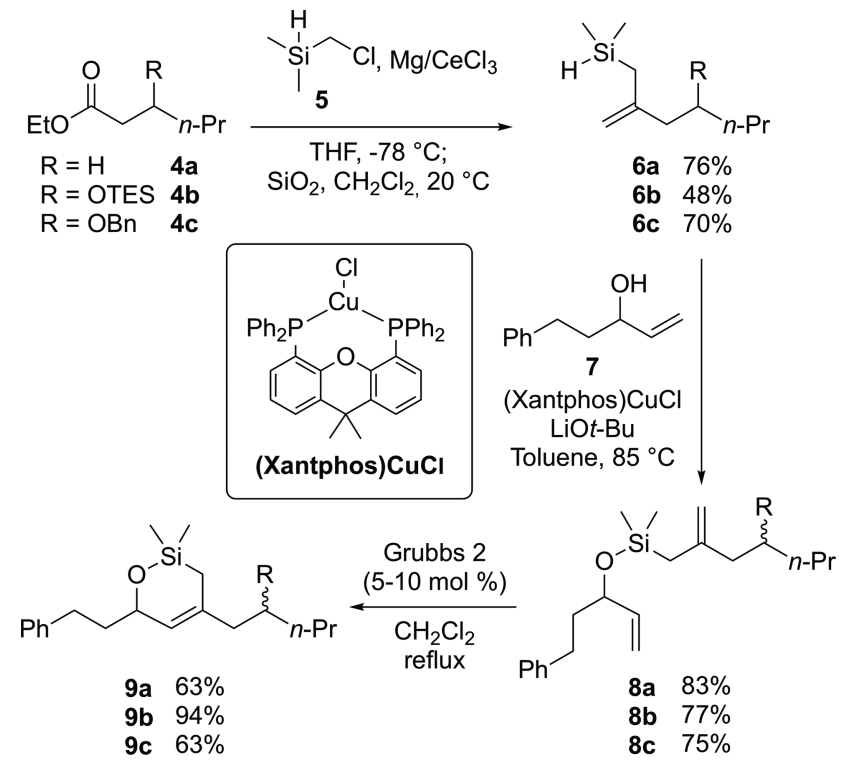

can be easily chlorinated, ${ }^{12 a}$ oxidized, ${ }^{12 b}$ or used in the hydrosilylation of alkynyl carbonyl compounds. ${ }^{12 c}$ Silanes $\mathbf{6 a -}$ c were reacted with allylic alcohol 7 under the dehydrogenative conditions reported by Ito and Sawamura et al. ${ }^{13}$ to furnish silyl ethers $\mathbf{8 a - c}$ in good yields (as 1:1 mixtures of diastereomers for $\mathbf{8 b}$ and $8 \mathrm{c}$ ). RCM of $8 \mathrm{a}-\mathrm{c}$ with $5-10 \mathrm{~mol}$ $\%$ of the Grubbs 2 catalyst proceeded uneventfully to furnish cyclic ethers $9 a-c$ in moderate to excellent yields.

Tether cleavage proved to be more difficult than anticipated. When compound $\mathbf{9 b}$ was subjected to the conditions employed by Miller and Li for the removal of their allylic silicon tether $\left(\mathrm{KF}, \mathrm{KHCO}_{3}, 1: 1 \mathrm{THF} / \mathrm{MeOH}\right),{ }^{8 \mathrm{a}}$ diol $10 \mathrm{~b}$ was obtained in $16 \%$ yield along with $41 \%$ of recovered $9 b$ (Scheme 3 ). All attempts to improve this yield by using alternative fluoride sources such as TBAF, KF, or CsF led to complete conversion to either isomerized product $\mathbf{1 1} \mathbf{b}$ or elimination product $\mathbf{1 2 b}$. When 9b was treated with $\mathrm{Sc}(\mathrm{OTf})_{3}$ in toluene, only elimination product $\mathbf{1 2} \mathbf{b}^{\prime}$ was formed.

We finally resorted to a two-step process to circumvent the problems described above. The six-membered ring of $9 a$ and 9c was first opened with methyllithium ${ }^{2 a}$ and the resulting allyltrimethylsilanes $13 a$ and $13 c$ were desilylated with TBAF in wet DMF at $65^{\circ} \mathrm{C}$, giving moderate yields of 10a and 10c
Scheme 3. Attempts at Tether Cleavage<smiles>CCCCC(C)OC(C)CCC1=C[C@H](CCc2ccccc2)O[Si](C)(C)C1</smiles>

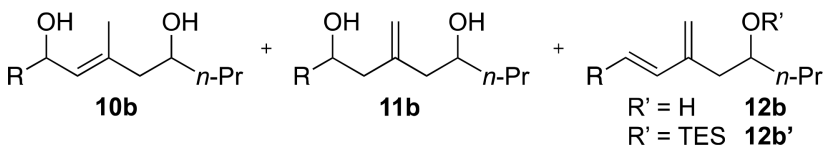

along with the corresponding isomerized 11a and 11c as easily separable minor products (Scheme 4).

Scheme 4. Tether Removal

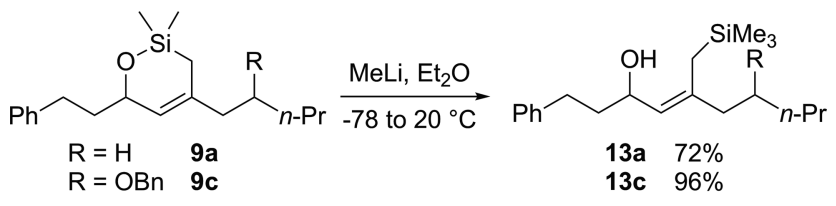

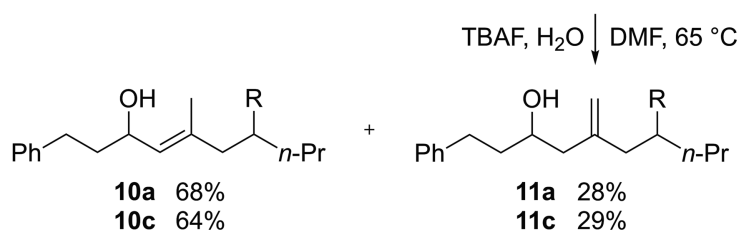

This new methodology can also be applied to the synthesis of trisubstituted olefins flanked by homoallylic alcohols. Silanes $6 \mathrm{a}$ and $6 \mathrm{c}$ were coupled with homoallylic alcohol $14 \mathrm{a}$ or $14 \mathrm{~b}$ under copper catalysis to give silyl ethers $15 \mathrm{aa}, 15 \mathrm{ac}$, and $15 \mathrm{ba}$ in good yields (Scheme 5). Formation of the seven-membered

Scheme 5. Synthesis of Trisubstituted Olefins Flanked by Homoallylic Alcohols

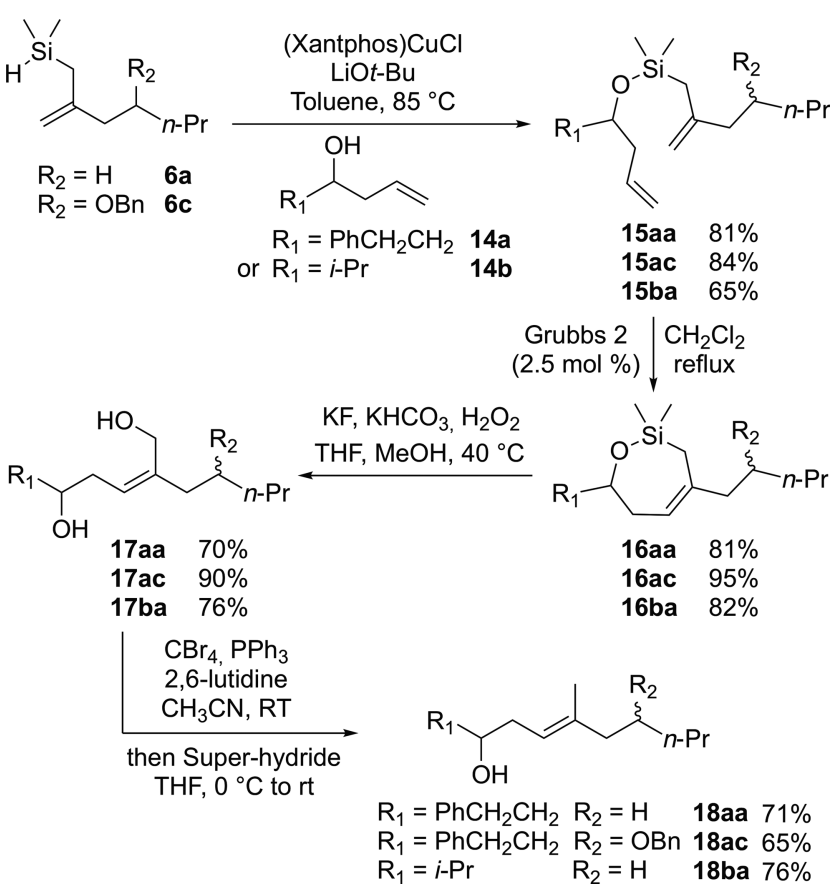


Scheme 6. Synthesis of the C16-C30 Fragment of Dolabelide C Using Silicon-Tether RCM
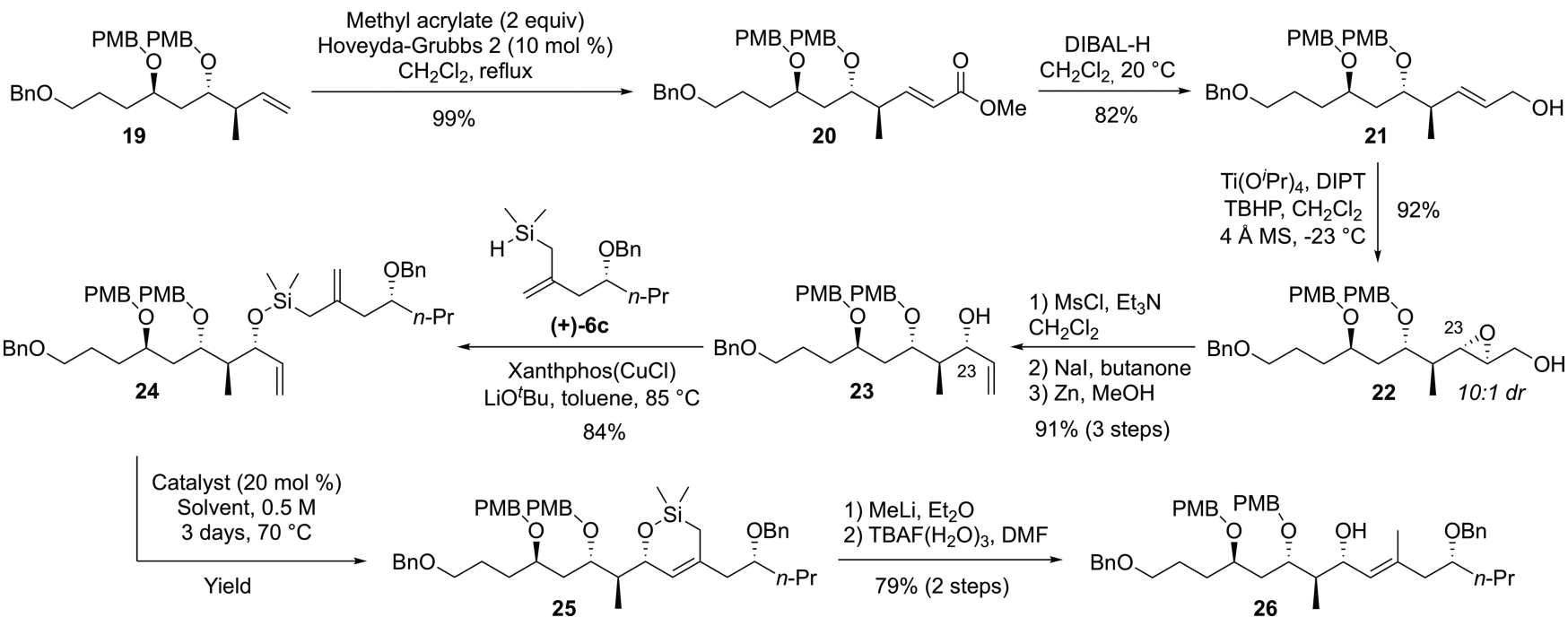

silyl ethers was easier than that of the corresponding sixmembered rings 16aa, 16ac, and 16ba, requiring only $2.5 \mathrm{~mol}$ $\%$ of Grubbs 2 catalyst. This is probably due to the lesser steric hindrance around the monosubstituted olefin, which is not branched at the allylic position in this case. When the two-step protocol for tether cleavage was performed on compounds 16, the desired homoallylic alcohols 18 were obtained as 1:1 inseparable mixtures with the corresponding isomerized products. Fortunately, Tamao-Kumada oxidation ${ }^{14}$ of the cyclic silyl ethers 16aa, 16ac, and 16ba furnished diols 17aa, $17 \mathrm{ac}$, and $17 \mathrm{ba}$ in good yields. Subsequent selective transformation of the primary alcohols into the corresponding bromides and reduction of these bromides (without intermediate purification) with Superhydride gave the desired homoallylic alcohols 18aa, 18ac, and 18ba.

We next turned to the synthesis of the C16-C30 fragment of dolabelide $\mathrm{C}$ using this silicon-tether RCM strategy. The synthesis started from compound $\mathbf{1 9}$ that we had prepared for our previous synthesis of this fragment ${ }^{5}$ (Scheme 6). Ozonolysis of the terminal alkene followed by vinyl Grignard addition to the resulting aldehyde afforded allylic alcohol 23 in good overall yield but as a 1:1 inseparable mixture of diastereomers at C23. To circumvent this problem, compound 19 was transformed into the corresponding primary allylic alcohol 21 via conjugated ester 20 by CM with methyl acrylate followed by DIBAL-H reduction of the ester. The C23 stereocenter was installed by Sharpless asymmetric epoxidation with 10:1 diastereoselectivity, and epoxide 22 was converted into the secondary allylic alcohol 23 by reduction of the intermediate iodoepoxide in $91 \%$ overall yield. ${ }^{15}$ Dehydrogenative coupling of alcohol 23 with silane $(+)-6 c^{16}$ furnished silyl ether $\mathbf{2 4}$ in good yield. When compound $\mathbf{2 4}$ was stirred with $20 \mathrm{~mol} \%$ of the Grubbs 2 catalyst in dichloromethane at reflux for 3 days, cyclic silyl ether $\mathbf{2 5}$ was obtained in only $43 \%$ yield, along with $23 \%$ recovered 24 (Table 1 , entry 1 ). Compound 24 features a branched allylic alcohol, which decreases its reactivity toward olefin metathesis compared to model substrates $8 \mathbf{a}-\mathbf{c}$. Performing the reaction at $70{ }^{\circ} \mathrm{C}$ in 1,2 dichloroethane slightly improved the yield (entry 2). Interestingly, changing the solvent to toluene improved both the conversion and the yield (entry 3 ). Higher temperatures and longer reaction times were not beneficial because they led
Table 1. Optimization of the RCM Reaction

\begin{tabular}{|c|c|c|c|}
\hline & & $\begin{array}{l}\mathrm{R}=\mathrm{H} \\
\mathrm{R}=\mathrm{SO}_{2} \mathrm{NMe}_{2} \\
\mathrm{R}=\mathrm{NO}_{2} \\
\mathrm{R}=\mathrm{NHCOO}_{-} \mathrm{Bu} \\
\mathrm{R}=\mathrm{NHCOCF}_{3}\end{array}$ & $\begin{array}{l}\text { Hoveyda-Grubbs } 2 \\
\text { Zhan } 1 \mathrm{~B} \\
\text { Nitro-Grela } \\
\text { Umicore } \mathrm{M}_{73} \text { SIMes } \\
\text { Umicore } \mathrm{M}_{71} \text { SIMes }\end{array}$ \\
\hline entry & catalyst & solvent & yield 25 \\
\hline 1 & Grubbs 2 & $\mathrm{CH}_{2} \mathrm{Cl}_{2}{ }^{a}$ & $43 \%(56 \% \text { brsm })^{b}$ \\
\hline 2 & Grubbs 2 & $1,2-\mathrm{DCE}^{c}$ & $57 \%(66 \%$ brsm $)$ \\
\hline 3 & Grubbs 2 & Toluene & $63 \%(78 \%$ brsm $)$ \\
\hline 4 & Hoveyda-Grubbs 2 & Toluene & $76 \%$ (87\% brsm) \\
\hline 5 & Zhan-1B & Toluene & $46 \%$ (58\% brsm) \\
\hline 6 & Nitro-Grela & Toluene & $79 \%$ (84\% brsm) \\
\hline 7 & Umicore $_{73}$ SIMes & Toluene & $74 \%$ (88\% brsm) \\
\hline 8 & Umicore $_{71}$ SIMes & Toluene & $81 \%$ (quant. brsm) \\
\hline
\end{tabular}

${ }^{a}$ Reaction performed at $40{ }^{\circ} \mathrm{C} .{ }^{b} \mathrm{brsm}=$ based on recovered starting material. ${ }^{c} \mathrm{DCE}=$ dichloroethane.

to decomposition of the silyl ethers. We then screened different Hoveyda-Grubbs type catalysts. The HoveydaGrubbs 2 catalyst improved the yield to $76 \%$ (entry 4). The Zhan-1B catalyst proved disappointing (entry 5), but the Nitro-Grela and the Umicore catalysts were superior (entries $6-8$ ), with an $81 \%$ yield obtained with the UmicoreM $_{71}$ SIMes complex. $^{17}$

Finally, the silicon tether was cleaved using solid TBAF in DMF, and compound $\mathbf{2 6}$ was obtained in $79 \%$ yield for the two steps, along with $13 \%$ of the isomerized product.

In conclusion, we have designed a silicon-tether ring-closing metathesis strategy for the efficient and diastereoselective synthesis of trisubstituted olefins flanked by allylic or homoallylic alcohols. During this study, we have developed a novel Peterson olefination reaction for the synthesis of allyldimethylsilanes. Finally, this new methodology was successfully applied to the synthesis of the C16-C30 fragment of dolabelide $\mathrm{C}$. 


\section{ASSOCIATED CONTENT}

\section{S Supporting Information}

The Supporting Information is available free of charge on the ACS Publications website at DOI: 10.1021/acs.orglett.8b03552.

Experimental procedures, characterization data and NMR spectra (PDF)

\section{AUTHOR INFORMATION}

\section{Corresponding Author}

*E-mail: joelle.prunet@glasgow.ac.uk.

\section{ORCID $\odot$}

Joëlle Prunet: 0000-0002-9075-971X

\section{Present Addresses}

† (S.W.) Institut de Chimie Moléculaire et des Matériaux d'Orsay, CNRS UMR 8182, Université Paris-Sud, Université Paris-Saclay, Bâtiment 420, 91405 Orsay cedex, France.

$\ddagger$ (A.A.) Omegachem, 480 Rue Perreault, Saint-Romuald, QC G6W 7 V6, Canada.

\section{Author Contributions}

${ }^{\S}$ A.F.T. and S.W. contributed equally.

Notes

The authors declare no competing financial interest.

\section{ACKNOWLEDGMENTS}

Financial support for this work was provided by the University of Glasgow and the EPSRC (Doctoral Training Allocations for A.F.T. EP/M508056/1, and for A.A. EP/K503058/1). We thank Umicore for a generous gift of a range of catalysts.

\section{REFERENCES}

(1) For total syntheses of callipeltoside A, see: (a) Trost, B. M.; Dirat, O.; Gunzner, J. L. Angew. Chem., Int. Ed. 2002, 41, 841. (b) Evans, D. A.; Hu, J.; Burch, J. D.; Jaeschke, G. J. Am. Chem. Soc. 2002, 124, 5654. (c) Trost, B. M.; Gunzner, J. L.; Dirat, O.; Rhee, Y. H. J. Am. Chem. Soc. 2002, 124, 10396. (d) Paterson, I.; Davies, R. D. M.; Heimann, A. C.; Marquez, R.; Meyer, A. Org. Lett. 2003, 5, 4477. (e) Huang, H.; Panek, J. S. Org. Lett. 2004, 6, 4383. (f) Evans, D. A.; Burch, J. D.; Hu, E.; Jaeschke, G. Tetrahedron 2008, 64, 4671. (g) Carpenter, J.; Northrup, A. B.; Chung, D.; Wiener, J. J. M.; Kim, S.-G.; MacMillan, D. W. C. Angew. Chem., Int. Ed. 2008, 47, 3568. (h) Hoye, T. R.; Danielson, M. E.; May, A. E.; Zhao, H. J. Org. Chem. 2010, 75, 7052. (i) Frost, J. R.; Pearson, C. M.; Snaddon, T. N.; Booth, R. A.; Ley, S. V. Angew. Chem., Int. Ed. 2012, 51, 9366. (j) Frost, J. R.; Pearson, C. M.; Snaddon, T. N.; Booth, R. A.; Turner, R. M.; Gold, J.; Shaw, D. M.; Gaunt, M. J.; Ley, S. V. Chem. - Eur. J. 2015, 21, 13261.

(2) For the total synthesis of dolabelide D, see: (a) Park, P. K.; O'Malley, S. J.; Schmidt, D. R.; Leighton, J. L. J. Am. Chem. Soc. 2006, 128, 2796. For the total synthesis of Dolabelide C, see: (b) Hanson, P. R.; Chegondi, R.; Nguyen, J.; Thomas, C. D.; Waetzig, J. D.; Whitehead, A. J. Org. Chem. 2011, 76, 4358. For the synthesis of fragments of dolabelides, see: (c) Schmidt, D. R.; Park, P. K.; Leighton, J. L. Org. Lett. 2003, 5, 3535. (d) Desroy, N.; Le Roux, R.; Phansavath, P.; Chiummiento, L.; Bonini, C.; Genêt, J.-P. Tetrahedron Lett. 2003, 44, 1763. (e) Le Roux, R.; Desroy, N.; Phansavath, P.; Genêt, J.-P. Synlett 2005, 429. (f) Roche, C.; Desroy, N.; Haddad, M.; Phansavath, P.; Genêt, J.-P. Org. Lett. 2008, 10, 3911. (g) Keck, G. E.; McLaws, M. D. Tetrahedron Lett. 2005, 46, 4911. (h) Waetzig, J. D.; Hanson, P. R. Org. Lett. 2008, 10, 109. (i) Whitehead, A.; Waetzig, J. D.; Thomas, C. D.; Hanson, P. R. Org. Lett. 2008, 10, 1421.
(3) Hoye, T. R.; Jeffrey, C. S.; Tennakoon, M. A.; Wang, J.; Zhao, H. J. Am. Chem. Soc. 2004, 126, 10210.

(4) For the synthesis of the C1-C15 fragment of dolabelide C, see: (a) Vincent, A.; Prunet, J. Synlett 2006, 2006, 2269. For the synthesis of the C16-C24 fragment of dolabelide C, see: (b) Grimaud, L.; de Mesmay, R.; Prunet, J. Org. Lett. 2002, 4, 419. For the synthesis of model C21-C24 or C21-C26 fragments of dolabelide C, see: (c) Grimaud, L.; Rotulo, D.; Ros-Perez, R.; Guitry-Azam, L.; Prunet, J. Tetrahedron Lett. 2002, 43, 7477. (d) Rotulo-Sims, D.; Prunet, J. Org. Lett. 2007, 9, 4147. (e) Oriez, R.; Prunet, J. Tetrahedron Lett. 2010, 51, 256. (f) Gamba-Sanchez, D.; Prunet, J. J. Org. Chem. 2010, 75, 3129.

(5) Braun, M.-G.; Vincent, A.; Boumediene, M.; Prunet, J. J. Org. Chem. 2011, 76, 4921.

(6) For a review on cross metathesis, see: Prunet, J.; Grimaud, L. Metathesis in Natural Product Synthesis; Cossy, J., Arseniyadis, S., Meyer, C., Eds.; Wiley: New York, 2010; p 287.

(7) (a) Evans, P. A.. Metathesis in Natural Product Synthesis; Cossy, J., Arseniyadis, S., Meyer, C., Eds.; Wiley: New York, 2010; p 225. (b) Cusak, A. Chem. - Eur. J. 2012, 18, 5800. (c) Jun, J. H.; Javed, S.; Ndi, C. N.; Hanson, P. R. Synthesis of Heterocycles by Metatehsis Reactions; Prunet, J., Ed.; Springer, 2017; p 319.

(8) (a) Li, F.; Miller, M. J. J. Org. Chem. 2006, 71, 5221. (b) Tung, J. C.; Chen, W.; Noll, B. C.; Taylor, R. E.; Fields, S. C.; Dent, W. H., III; Green, F. R. Synthesis 2007, 2007, 2388.

(9) For recent examples in synthesis of natural products, see: (a) Benimana, S. E.; Cromwell, N. E.; Meer, H. N.; Marvin, C. C. Tetrahedron Lett. 2016, 57, 5062. (b) Tanis, P. S.; Infantine, J. R.; Leighton, J. L. Org. Lett. 2013, 15, 5464. (c) Clark, J. S.; Romiti, F. Angew. Chem., Int. Ed. 2013, 52, 10072. (d) Xuan, M.; Paterson, I.; Dalby, S. Org. Lett. 2012, 14, 5492.

(10) Narayanan, B. A.; Bunnelle, W. H. Tetrahedron Lett. 1987, 28, 6261.

(11) Synthesis of $\mathbf{6 b}$ was not optimized.

(12) (a) Gossage, R. A.; Muñoz-Martínez, E.; van Koten, G., van Tetrahedron Lett. 1998, 39, 2397. (b) Limnios, D.; Kokotos, C. G. ACS Catal. 2013, 3, 2239. (c) Trost, B. M.; Ball, Z. T. J. Am. Chem. Soc. 2004, 126, 13942.

(13) Ito, H.; Watanabe, A.; Sawamura, M. Org. Lett. 2005, 7, 1869.

(14) Fujiwara, T.; Yanai, K.; Shimane, K.; Takamori, M.; Takeda, T. Eur. J. Org. Chem. 2001, 2001, 155.

(15) Yadav, J. S.; Haldar, A.; Maity, T. Eur. J. Org. Chem. 2013, 2013, 3076.

(16) The synthesis of (+)-6c is described in the Supporting Information.

(17) The Zhan-1B, Nitro-Grela, and Umicore catalysts are all commercially available. 